Review / Meta-analyses

\title{
Effectiveness of CBT for children and adolescents with depression: A systematic review and meta-regression analysis
}

\author{
Matthijs Oud ${ }^{\mathrm{a}, *}$, Lars de Winter ${ }^{\mathrm{b}}$, Evelien Vermeulen-Smit ${ }^{\mathrm{c}}$, Denise Bodden ${ }^{\mathrm{d}}$, \\ Maaike Nauta ${ }^{\mathrm{e}}$, Lisanne Stone ${ }^{\mathrm{f}}$, Marieke van den Heuvel ${ }^{\mathrm{g}}$, Reham Al Taher ${ }^{\mathrm{h}}$, \\ Ireen de Graaf ${ }^{\mathrm{i}}$, Tim Kendall ${ }^{\mathrm{j}}$, Rutger Engels ${ }^{\mathrm{k}}$, Yvonne Stikkelbroek ${ }^{\mathrm{d}}$ \\ a Department of Reintegration, Trimbos-Institute, Da Costakade 45, 3521 VS Utrecht, the Netherlands \\ ${ }^{\mathrm{b}}$ Phrenos Center of Expertise, Da Costakade 45, 3521 VS Utrecht, the Netherlands \\ ${ }^{\mathrm{c}}$ Christian University of Applied Sciences Ede, P.O. Box 80, 6710 BB, Ede, the Netherlands \\ d Child and Adolescent Studies, University of Utrecht, P.O. Box 80.140, 3508 TC Utrecht, the Netherlands \\ e Department of Clinical Psychology, Faculty of Behavioural and Social Sciences, University of Groningen, Grote Kruisstraat 2/1, 9712 TS Groningen, the \\ Netherlands \\ ${ }^{\mathbf{f}}$ Karakter kinder- en jeugdpsychiatrie, Reinier Postlaan 12, 6525 GC Nijmegen, the Netherlands \\ ${ }^{g}$ Department of Public Mental Health, Trimbos-Institute, Da Costakade 45, 3521 VS Utrecht, the Netherlands \\ ${ }^{\mathrm{h}}$ Psychologist for Jung Institute for Free Analysis for Children and Adolescence, 8 St. Mary's Road, Crumlin, Dublin 12, Ireland \\ ${ }^{i}$ Department of Public Mental Health, Trimbos-Institute, Postbus 725, 3500 AS Utrecht, the Netherlands \\ ${ }^{\mathrm{j}}$ National Clinical Director for Mental Health, NHS England, Wellington House, 133-155 Waterloo Road, London, SE1 8UG, United Kingdom \\ ${ }^{\mathrm{k}}$ Rector Magnificus, Erasmus Universiteit Rotterdam, Postbus 1738, 3000 DR Rotterdam, the Netherlands
}

\section{A R T I C L E I N F O}

\section{Article history:}

Received 14 September 2018

Received in revised form 27 December 2018

Accepted 28 December 2018

Available online 16 January 2019

\section{Keywords:}

Review

Meta-analysis

CBT

Children

Adolescents

Depression

\begin{abstract}
A B S T R A C T
Background: Cognitive-behavioral therapy (CBT) is first choice of treatment for depressive symptoms and disorders in adolescents, however improvements are necessary because overall efficacy is low. Insights on CBT components and contextual and structural characteristics might increase the efficacy. The aim of our approach is to evaluate the efficacy of CBT for youth with depression and investigate the influence of specific components, contextual and structural factors that could improve effects. Methods: A systematic review of randomized controlled trials was conducted, searches were undertaken in CINAHL, CENTRAL, EMBASE, MEDLINE/PubMed and PsycINFO. Outcomes were meta-analyzed and confidence in results was assessed using the GRADE-method. Meta-regression was used to pinpoint components or other factors that were associated with an in- or decrease of effects of CBT.

Results: We included 31 trials with 4335 participants. Moderate-quality evidence was found for CBT reducing depressive symptoms at the end of treatment and at follow-up, and CBT as indicated prevention resulted in $63 \%$ less risk of being depressed at follow-up. CBT containing a combination of behavioral activation and challenging thoughts component (as part of cognitive restructuring) or the involvement of caregiver(s) in intervention were associated with better outcomes for youth on the long term. Conclusions: There is evidence that CBT is effective for youth with a (subclinical) depression. Our analyses show that effects might improve when CBT contains the components behavioral activation and challenging thoughts and also when the caregiver(s) are involved. However, the influential effects of these three moderators should be further tested in RCTs.
\end{abstract}

(C) 2018 Elsevier Masson SAS. All rights reserved.

\footnotetext{
* Corresponding author.

E-mail addresses: matthijsoud@gmail.com (M. Oud), ldewinter@kcphrenos.nl (L. de Winter), evermeulen@che.nl (E. Vermeulen-Smit), D.Bodden@uu.nl (D. Bodden),

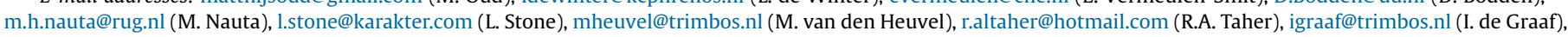
tim2.kendall@virgin.net (T. Kendall), rutger.engels@eur.nl (R. Engels), Y.Stikkelbroek@uu.nl (Y. Stikkelbroek).
} 


\section{Introduction}

Youth depression is one of the most prevalent disorders in children and adolescents. The prevalence rate in childhood is about $2.8 \%$, and increases during the course of adolescence (5.6\%) [1]. Research has shown no gender differences in prevalence rates of depressive disorders in children, but the rate is twice as high in adolescent girls compared to boys [2]. Depression has a high burden of disease [3], an increased risk of suicide [4], development of disruptive behaviors, problematic substance use [5], poor school performance and social functioning [6]. A major concern is that almost $50 \%$ of adolescents who have a depressive episode will have a recurrence within five years [7]. Therefore, evidence-based treatment for youth with depression is essential.

Most pharmacological treatment have an unfavorable riskbenefit profile, their use is often not effective and controversial due to the possible increased suicide risk [8]. Therefore evidencebased psychological interventions are often the first choice of treatment. For example, NICE guidelines recommend cognitive behavioral therapy (CBT) as an evidence-based psychological intervention for mild, moderate and severe depression [9]. Although CBT is effective, several meta-analyses have shown that effect sizes are small to moderate when utilized as indicated prevention for youth [10] or treatment for children [11] and adolescents [12]. So far, other treatments have not led to larger effect sizes. For instance, interpersonal psychotherapy (IPT) has not been shown to be more effective than CBT as a treatment for adolescent depression [13].

So the next step in psychological intervention research is to identify effective mechanisms of existing psychological interventions in order to enhance the effectiveness [14], for a substantial proportion of youths with depression it's especially relevant to help increase the limited effectiveness of CBT. It is possible to test differential effectiveness of CBT because CBT protocols are known to vary in the presence of different components, and contextual and structural factors [15]. For example, the Problem Solving For Life Project intervention [16] does not have relaxation and challenging thoughts as part of treatment and 'On Full Power' [17] does, and the CBT intervention in the 'Treatment of Adolescents with Depression Study' does involve parents and the 'Coping with depression for adolescents' doesn't [18]. Some work has been done to identify influential factors on treatment outcome in recent reviews $[10,11,19,20]$, but none of these studies have investigated if a certain individual component or a combination of intervention components improve the effectiveness of CBT.

Building the body of evidence for these influential factors, can help to personalize CBT so it can better fit the individual child or adolescent, which may potentially reduce costs and prevent harm by reducing the use of non-effective or counterproductive components of CBT in youth.

The aim of the current systematic review and meta-analysis is to identify components of CBT, as well as contextual and structural factors, which could influence treatment outcomes of CBT. We therefore set out to systematically identify controlled studies on the effectiveness of CBT in youth with clinical and subclinical symptoms of depression. Moreover, all CBT intervention protocols were rated for the presence of specific intervention components, and contextual and structural factors.

\section{Methods}

This review is conducted according the Preferred Reporting Items for Systematic Reviews and Meta-analyses (PRISMA) guidelines [21] (Appendix A for the PRISMA-checklist).

\subsection{Eligibility criteria}

We pre-specified our inclusion and exclusion criteria and included randomized controlled trials (RCTs) investigating CBT as an indicated prevention or treatment intervention for youth with subclinical depressive symptoms or with a clinical depressive disorder. CBT must have been delivered to children and adolescents (and caregiver(s)). At least one control condition in the study had to be an inactive intervention (for example, waitlist, no intervention, placebo, monitoring or an attention control group). Active control interventions (including treatment as usual) were not included due to the amount of expected heterogeneity it would create in the meta-regression and because a head to head comparator contain elements of CBT. Also, the majority of active control interventions contained some elements of CBT, mostly combined with other non-CBT elements. This comparison would not give a representative insight into the efficacy of specific CBT elements. Therefore, only passive control groups, without any type of CBT elements, were included into the study. Furthermore, only articles that were written in English or Dutch were included. Finally, RCTs from before 1990 were excluded because we expected intervention protocols to be irretrievable before this date.

\subsection{Search strategy}

CINAHL, CENTRAL (Cochrane), EMBASE, MEDLINE/PubMed and PsycINFO (including dissertation abstracts) were searched from inception to the 4th of September 2017. The searches were undertaken by a librarian using terms for children and adolescents, depression, randomized controlled trials, systematic reviews and meta-analyses; all search strings are reported in Appendix B. We then searched the reference lists of all the included and excluded studies and previous systematic reviews and meta-analysis. We also contacted authors of studies to request additional data. Two authors (LdW, RAT/MO) independently performed the title/ abstract and full text selection, and disagreements were resolved through consensus.

\subsection{Assessment of bias and confidence in results}

Each included study was assessed independently by two authors (LdW, RAT/MO) using the Cochrane Collaboration Risk of Bias Assessment Tool [22]. The level of agreement was moderate $(\kappa=0.60)$. Disagreements were resolved by consensus. Each study was rated for risk of bias ( $\mathrm{RoB})$ on sequence generation, allocation concealment, masking of participants, assessors and providers, selective outcome reporting and incomplete data. RoB for each domain was rated as high (seriously weakens confidence in the effect estimate), low (unlikely to seriously alter the effect estimate), or unclear.

Confidence in the effect estimates of the meta-analysis were assessed by MO and LdW using the Grading of Recommendations Assessment, Development and Evaluation (GRADE) method [23], which is a structured assessment of the quality of evidence attending to the following factors: RoB, inconsistency, indirectness, imprecision and publication bias. Outcomes can be 'downgraded', based on the aforementioned factors resulting in 'high', 'moderate', 'low' or 'very low' confidence in the effect estimate.

\subsection{Data management}

Outcome measures included depressive symptoms, quality of life, number of youth diagnosed with a depressive disorder, recovery (no longer meeting DSM criteria), remission (different criteria of symptom decrease on various scales), response (Clinical Global Impressions-Improvement scale of (very) much improved) 
rate. The continuous measures are listed in Appendix C. If outcome data were missing or could not be used in the meta-analyses, authors were asked to provide additional data. We also extracted the following: the country in which the study was undertaken, setting, intervention format (face-to-face, bibliotherapy, online, and individual/group-based), number and length of sessions, attrition rate and participant details (mean age, proportion of females, proportion of participants using antidepressants at baseline, and proportion of participants with a diagnosis of major depressive disorder (MDD), dysthymia and/or comorbid anxiety disorder).

Most articles don't provide detailed information regarding the investigated protocol [15]. It's often unclear which modules of CBT are used, how the intervention was given and in which dosage. Since we were interested in this information, we developed a taxonomy to rate protocols. This taxonomy consists of a checklist in which different aspects of a protocol can be screened, namely CBT components (psychoeducation, cognitive restructuring, behavioral activation, monitoring, problem solving, relaxation, social skills, positive reinforcement (reward), modelling, setting goals, relapse prevention), contextual factors (for example, target population, target, theory) and structural factors (for example, content, dose, frequency, sequence). The content of the taxonomy is based on work of Chorpita and colleagues [24-26], and expert consensus. We used this taxonomy to rate protocol manuals.

Protocol manuals were requested by contacting the primary investigator or a co-author of the included studies. The taxonomy was applied to four of these manuals by three raters (DB and two pedagogs) trained in CBT. Additionally they received a training in the taxonomy explaining the specific parts and pitfalls. After the four manuals were rated, there was a meeting in which the raters discussed the agreements and disagreements. Some aspects of the taxonomy were adapted for clarification purposes. Also, some aspects of the taxonomy were difficult to rate (e.g. the dosage of each step of a specific component), therefor they were deleted. The four manuals were rated again and high consensus (90\%) was obtained. Then, the two raters supervised by DB applied the taxonomy to the remaining manuals individually. It is unclear to which extent the manuals were actually applied in the included studies.

\subsection{Statistical analysis}

\subsubsection{Meta-analysis}

We conducted meta-analyses for different comparison groups and outcome types using Review Manager (RevMan) 5.3 [27].

\section{Flow Chart search depression}
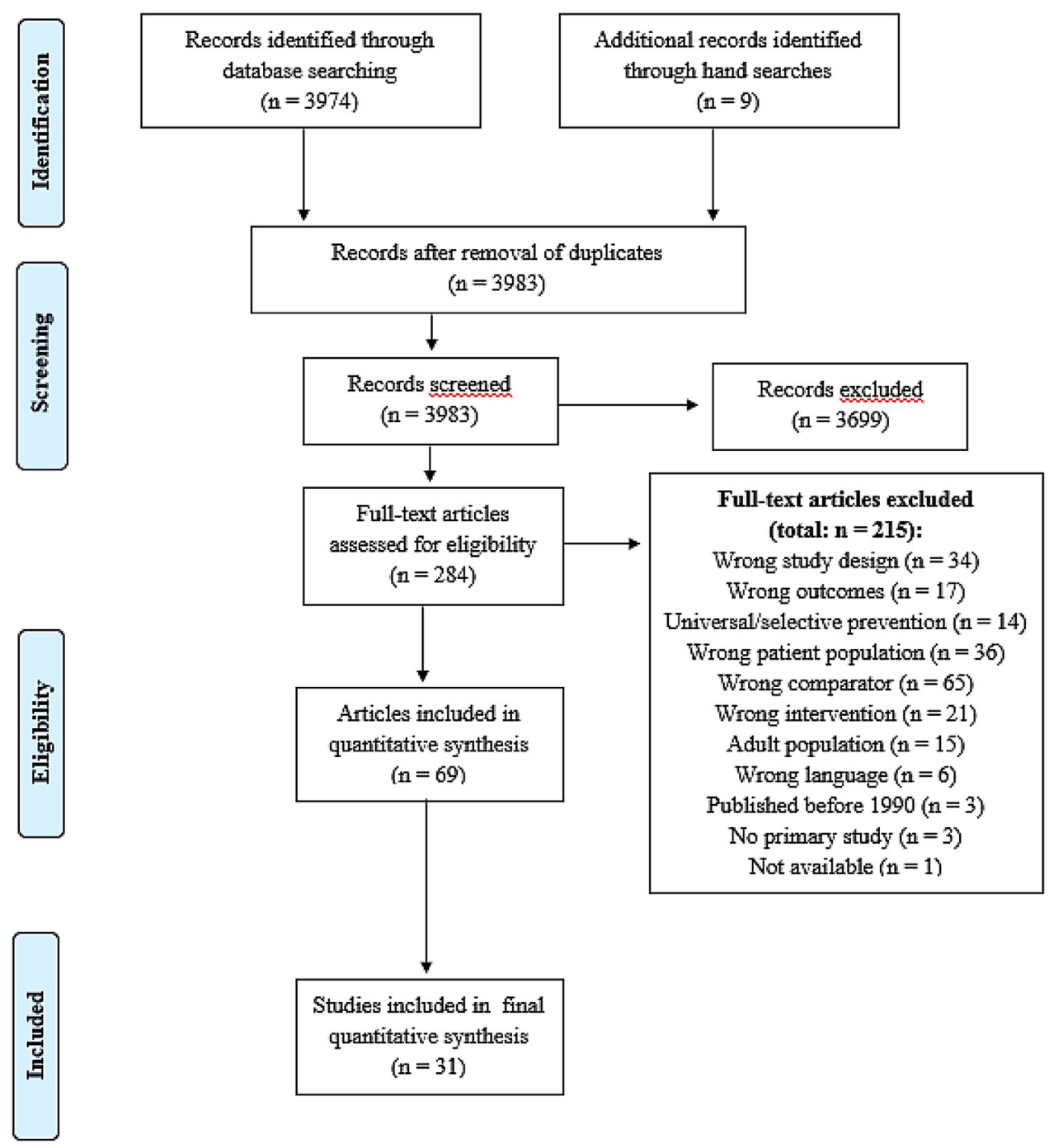

Fig. 1. Flow Chart. 
Table 1a

Study characteristics per study.

\begin{tabular}{|c|c|c|c|c|c|c|c|c|c|c|c|}
\hline Study name & Country* & Setting & Meanage & $\begin{array}{l}\% \\
\text { Female }\end{array}$ & Intervention name* & $\begin{array}{l}\text { Indicated } \\
\text { or } \\
\text { treatment }\end{array}$ & Format & $\begin{array}{l}\mathrm{N} \text { total } \\
\text { per arm }\end{array}$ & $\begin{array}{l}\text { Attrition } \\
\text { (\%) per } \\
\text { arm }\end{array}$ & $\begin{array}{l}\text { Number } \\
\text { of } \\
\text { sessions }\end{array}$ & $\begin{array}{l}\text { Duration } \\
\text { (weeks) }\end{array}$ \\
\hline Ackerson 1998 & USA & Home & 15.93 & 64 & FG & Indicated & $\begin{array}{l}\text { Bibliotherapy, } \\
\text { individual }\end{array}$ & $15 / 15$ & $20 / 33$ & NR & 4 \\
\hline Asarnow 2002 & USA & School & NR & 65 & SB bibliotherapy & Indicated & $\begin{array}{l}\text { FTF, family } \\
\text { based }\end{array}$ & & NR & 10 & 5 \\
\hline $\begin{array}{l}\text { Charkandeh } \\
2016\end{array}$ & Iran & $\begin{array}{l}\text { Mental health } \\
\text { institution }\end{array}$ & 15.27 & 54 & CBT & Treatment & FTF, individual & $65 / 60$ & $0 / 0$ & 12 & 12 \\
\hline Clarke 1999 & USA & University clinic & NR & NR & $\begin{array}{l}\text { CWD-A manual } \\
\text { adolescent only }\end{array}$ & Treatment & $\begin{array}{l}\text { FTF, group } \\
\text { based }\end{array}$ & $45 / 18$ & $18 / 25$ & 16 & 8 \\
\hline Clarke 1999 & USA & University clinic & NR & NR & $\begin{array}{l}\text { CWDA manual } \\
\text { adolescent + caregiver }\end{array}$ & Treatment & $\begin{array}{l}\text { FTF, group } \\
\text { based }\end{array}$ & $42 / 18$ & $24 / 25$ & 16 & 8 \\
\hline $\begin{array}{l}\text { De Cuyper } \\
2004\end{array}$ & $\mathrm{BE}$ & University clinic & 10.00 & 75 & TA & Indicated & $\begin{array}{l}\text { FTF, group } \\
\text { based }\end{array}$ & $11 / 11$ & $0 / 0$ & 16 & 16 \\
\hline Fleming 2012 & $\mathrm{NZ}$ & School & 14.9 & 44 & SPARX & Indicated & $\begin{array}{l}\text { Online, } \\
\text { individual }\end{array}$ & $20 / 12$ & $20 / 8$ & 7 & NR \\
\hline Hoek 2009 & NL & Home & 16.08 & 76 & PST & Indicated & $\begin{array}{l}\text { Online, } \\
\text { individual }\end{array}$ & $22 / 23$ & $41 / 35$ & 5 & 5 \\
\hline $\begin{array}{l}\text { Kaesornsamut } \\
2012\end{array}$ & $\mathrm{TH}$ & School & 16.9 & 48 & BAND & Indicated & $\begin{array}{l}\text { FTF, group } \\
\text { based }\end{array}$ & $30 / 30$ & $0 / 0$ & 14 & 7 \\
\hline Kahn 1990 & USA & School & NR & 52 & CBT & Treatment & $\begin{array}{l}\text { FTF, group } \\
\text { based }\end{array}$ & $17 / 17$ & $0 / 0$ & 12 & NR \\
\hline Kerfoot 2004 & UK & $\begin{array}{l}\text { Mental health } \\
\text { institution }\end{array}$ & 13.88 & 46 & CBT & Treatment & FTF, individual & $45 / 41$ & $10 / 13$ & 8 & 8 \\
\hline Lamb 1998 & USA & School & 15.8 & 56 & CSG & Indicated & $\begin{array}{l}\text { FTF, group } \\
\text { based }\end{array}$ & $23 / 18$ & $15 / 5$ & NR & 8 \\
\hline $\begin{array}{l}\text { Lewinsohn } \\
1990\end{array}$ & USA & NR & 16.27 & 61 & CWD-A manual & Treatment & $\begin{array}{l}\text { FTF, group } \\
\text { based }\end{array}$ & $19 / 9$ & NR & 14 & 7 \\
\hline $\begin{array}{l}\text { Lewinsohn } \\
1990\end{array}$ & USA & NR & 16.21 & 65 & CWD-A manual & Treatment & $\begin{array}{l}\text { FTF, group } \\
\text { based }\end{array}$ & $21 / 10$ & NR & 14 & 7 \\
\hline Liddle 1990 & $\mathrm{AU}$ & School & 9.2 & 48 & SCT & Indicated & $\begin{array}{l}\text { FTF, group } \\
\text { based }\end{array}$ & $11 / 10$ & NR & 8 & 8 \\
\hline Rossello 1999 & UK & University clinic & NR & NR & CBT & Treatment & FTF, individual & $25 / 23$ & $16 / 22$ & 12 & 12 \\
\hline Sheffield 2006 & $\mathrm{AU}$ & School & NR & NR & PSL & Indicated & $\begin{array}{l}\text { FTF, group } \\
\text { based }\end{array}$ & $\begin{array}{l}134 / \\
149\end{array}$ & $16 / 9$ & 8 & 8 \\
\hline Smith 2015 & UK & School & NR & NR & Computerized CBT & Indicated & $\begin{array}{l}\text { Online, } \\
\text { individual }\end{array}$ & $55 / 57$ & $0 / 4$ & NR & 8 \\
\hline Stice 2008 & USA & School & NR & NR & 6-CDPI & Indicated & $\begin{array}{l}\text { FTF, group } \\
\text { based }\end{array}$ & $89 / 42$ & $1 / 1$ & 6 & 6 \\
\hline Stice 2008 & USA & School & NR & NR & FG bibliotherapy & Indicated & $\begin{array}{l}\text { Bibliotherapy, } \\
\text { individual }\end{array}$ & $80 / 42$ & $5 / 1$ & NR & NR \\
\hline Weisz 1997 & USA & School & 9.6 & 46 & PASCET & Indicated & $\begin{array}{l}\text { FTF, group } \\
\text { based }\end{array}$ & $16 / 32$ & NR & 8 & 8 \\
\hline $\begin{array}{l}\text { Wijnhoven } \\
2014\end{array}$ & NL & School & 13.3 & 100 & OVK & Indicated & $\begin{array}{l}\text { FTF, group } \\
\text { based }\end{array}$ & $59 / 59$ & NR & 8 & 8 \\
\hline Yu 2002 & $\mathrm{CH}$ & School & 11.86 & 45 & POP & Indicated & $\begin{array}{l}\text { FTF, group } \\
\text { based }\end{array}$ & $104 / 116$ & $3 / 2$ & 10 & 10 \\
\hline \multicolumn{12}{|c|}{ Versus attention control } \\
\hline Brent 1998 & USA & $\begin{array}{l}\text { Mental health } \\
\text { institution }\end{array}$ & 15.6 & 76 & CTDSY & Treatment & $\begin{array}{l}\text { FTF, family } \\
\text { based }\end{array}$ & $37 / 35$ & $19 / 31$ & 16 & 16 \\
\hline Dobson 2010 & $\mathrm{CA}$ & School & 15.26 & 69 & ACSC & Indicated & $\begin{array}{l}\text { FTF, group } \\
\text { based }\end{array}$ & $25 / 21$ & $0 / 0$ & 15 & NR \\
\hline Ip 2016 & HK & Home & 14.63 & 68 & GO & Indicated & $\begin{array}{l}\text { Online, } \\
\text { individual }\end{array}$ & $\begin{array}{l}130 / \\
127\end{array}$ & NR & 10 & NR \\
\hline Kaufman 2005 & USA & $\begin{array}{l}\text { Children and } \\
\text { adolescents' } \\
\text { healthcare }\end{array}$ & 15.1 & 48 & CWD-A manual & Treatment & $\begin{array}{l}\text { FTF, group } \\
\text { based }\end{array}$ & $45 / 48$ & $2 / 2$ & 16 & 8 \\
\hline Stallard 2012 & UK & School & NR & NR & RAP & Indicated & $\begin{array}{l}\text { FTF, group } \\
\text { based }\end{array}$ & $\begin{array}{l}392 / \\
374\end{array}$ & NR & 9 & NR \\
\hline Szigethy 2014 & USA & $\begin{array}{l}\text { Children and } \\
\text { adolescents' } \\
\text { healthcare }\end{array}$ & 14.3 & 53 & ATS & Treatment & $\begin{array}{l}\text { FTF, family } \\
\text { based }\end{array}$ & $110 / 107$ & $18 / 18$ & 12 & 12 \\
\hline Vostanis 1996 & UK & $\begin{array}{l}\text { Mental health } \\
\text { institution }\end{array}$ & 12.7 & 56 & CBT (Vostanis) & Treatment & FTF, individual & $29 / 28$ & $0 / 0$ & 9 & 18 \\
\hline Wright 2017 & UK & Home & 15.35 & 66 & SB & Indicated & $\begin{array}{l}\text { Online, } \\
\text { individual }\end{array}$ & $45 / 46$ & NR & 8 & NR \\
\hline \multicolumn{12}{|c|}{ Versus monitoring control } \\
\hline $\begin{array}{l}\text { Marchand } \\
2010\end{array}$ & USA & School & 15.5 & 58 & MEP & Indicated & $\begin{array}{l}\text { FTF, group } \\
\text { based }\end{array}$ & $86 / 81$ & NR & 6 & 6 \\
\hline $\begin{array}{l}\text { Poppelaars } \\
2016\end{array}$ & NL & School & 13.24 & 100 & SPARX & Indicated & $\begin{array}{l}\text { Online, } \\
\text { individual }\end{array}$ & $51 / 17$ & $4 / 0$ & NR & 7 \\
\hline $\begin{array}{l}\text { Poppelaars } \\
2016\end{array}$ & NL & School & 13.32 & 100 & OVK & Indicated & $\begin{array}{l}\text { FTF, group } \\
\text { based }\end{array}$ & $50 / 17$ & $4 / 0$ & 8 & 8 \\
\hline $\begin{array}{l}\text { Poppelaars } \\
2016\end{array}$ & $\mathrm{NL}$ & School & 13.35 & 100 & SPARX + OVK & Indicated & $\begin{array}{l}\text { Online and } \\
\text { FTF group } \\
\text { based }\end{array}$ & $56 / 17$ & $5 / 0$ & 8 & 8 \\
\hline
\end{tabular}


Table 1a (Continued)

\begin{tabular}{|c|c|c|c|c|c|c|c|c|c|c|c|}
\hline Study name & Country* & Setting & Meanage & $\begin{array}{l}\% \\
\text { Female }\end{array}$ & Intervention name* & $\begin{array}{l}\text { Indicated } \\
\text { or } \\
\text { treatment }\end{array}$ & Format & $\begin{array}{l}\mathrm{N} \text { total } \\
\text { per arm }\end{array}$ & $\begin{array}{l}\text { Attrition } \\
\text { (\%) per } \\
\text { arm }\end{array}$ & $\begin{array}{l}\text { Number } \\
\text { of } \\
\text { sessions }\end{array}$ & $\begin{array}{l}\text { Duration } \\
\text { (weeks) }\end{array}$ \\
\hline Rohde 2014 & USA & School & NR & NR & MEP CBT & Indicated & $\begin{array}{l}\text { FTF, group } \\
\text { based }\end{array}$ & $126 / 62$ & NR & 6 & 6 \\
\hline Rohde 2014 & USA & School & NR & NR & MEP bibliotherapy & Indicated & $\begin{array}{l}\text { Bibliotherapy, } \\
\text { individual }\end{array}$ & $128 / 62$ & NR & NR & NR \\
\hline \multicolumn{12}{|c|}{ Versus placebo } \\
\hline March 2004 & USA & $\begin{array}{l}\text { Mental health } \\
\text { institution }\end{array}$ & 14.6 & 54 & TADS CBT & Treatment & FTF, individual & $111 / 112$ & $22 / 13$ & 12 & 12 \\
\hline
\end{tabular}

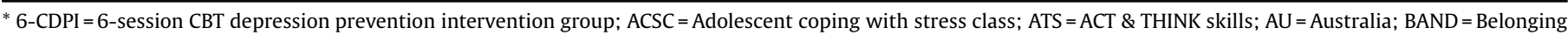

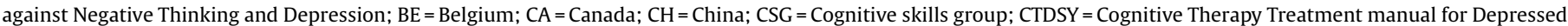

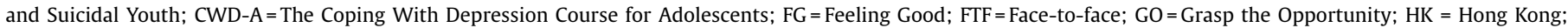

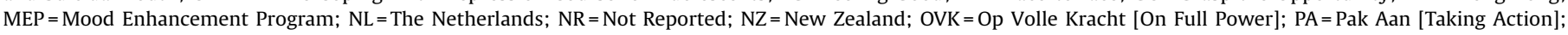

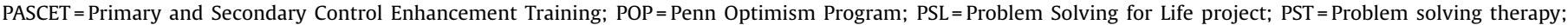

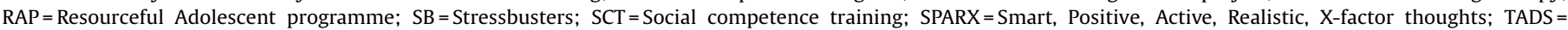
Treatment for Adolescents With Depression Study; UK=United Kingdom; USA=United States of America; $\mathrm{TH}=\mathrm{Thailand}$.

Overall effects were calculated using random effects models and weighted by the inverse of variance [22]. For continuous outcomes, we calculated the standardized mean difference (SMD), Hedges' $g$, for between-group differences. SMDs were considered small $(0.2 \leq \mathrm{SMD}<0.5)$, medium $(0.5 \leq \mathrm{SMD}<0.8)$ or large $(\mathrm{SMD} \geq 0.8)$ [28]. For dichotomous outcomes, we calculated the risk ratio (RR) for events. All outcomes were reported with 95\% confidence intervals (CIs). Statistical heterogeneity was assessed by MO by visual inspection of forest plots, by performing the $\chi 2$ test (assessing the $95 \% \mathrm{CIs}$ ), and by calculating the $\mathrm{I}^{2}$ statistic, which describes the percentage of observed heterogeneity that would not be expected by chance. $\mathrm{I}^{2}$ was considered moderate if it exceeded $50 \%$ and high if it was more than $75 \%$ [29].

\subsubsection{Meta-regression}

To explain heterogeneity, and assess which CBT components or contextual and structural factors influence the overall efficacy of the CBT intervention, a meta-regression analysis was performed using STATA 12.1 [30]. Due to the large number of variables that could be used and the limited studies available, we had to limit these variables to prevent type 1 errors [31]. Therefore, we decided to perform two separate meta-regressions: one on CBT components and another on the contextual and structural factors; both meta-regressions would include the type of control condition and RoB. To further limit the number of included variables, a prespecified hierarchy (Appendix D) was prepared that was based on children and adolescents' views on the effectiveness and feasibility of intervention components [32] and clinical expert opinion from DB and YS. Finally, we determined that there should be a sufficient distribution of the presence or absence of variables between studies, within a study we chose for an arbitrary cut-off of at least $15 \%$ meeting one of the dichotomous criteria (15-85 ratio). Potential collinearity between the included variables was assessed by calculating the associations between the variables using a Spearman correlation matrix. For variables that were significantly associated with each other, the correlating variable that was lower on the pre-specified hierarchy of important variables was removed from the meta-regression model.

\section{Results}

\subsection{Study flow}

Of the 3974 potentially relevant citations from our database search, and nine through our hand search, we retrieved 284 fulltext articles. A total of 215 articles were excluded in the full-text selection because of ineligible study design $(k=34)$, irrelevant outcomes $(\mathrm{k}=17)$, the intervention was universal or selective prevention $(\mathrm{k}=14)$ or not CBT $(\mathrm{k}=21)$, participant samples that did not match our target population $(\mathrm{k}=51)$, active comparison condition $(k=65)$, the article was not reported in English or Dutch $(\mathrm{k}=6)$, the article was published before $1990(\mathrm{k}=3)$, the article reported on an already included study with no new results $(k=3)$ and study data were not available $(\mathrm{k}=1)$. The 69 remaining articles, published between 1990 and 2017, reported on results of 31 studies. More information about the study flow can be found in Fig. 1.

\subsection{Study and intervention characteristics}

Of the 31 studies $(n=4335)$ included in the quantitative syntheses, a total number of 2369 participants were randomized into the CBT intervention group and 1966 participants into the control group. The mean age of the 4335 participants was 14.2 years. Further study characteristics are reported per included study in Table 1a and summarized in Table 1b.

Thirty-seven CBT intervention arms containing 27 different types of CBT protocols were identified. If the protocol was not available $(\mathrm{k}=12)$, the information within the published article was used to identify characteristics of CBT. If information on intervention components could not be identified it was labelled as missing/ unclear. Table 2 provides a short description of context and structure characteristics of CBT, and an overview per intervention of the different components of CBT included in the metaregression analysis.

\subsection{Risk of bias}

Thirty trials were labelled as having a 'high' RoB and 1 trial as having a 'low' RoB. An overview of RoB criteria scores per included study is presented in Table $3 \mathrm{a}$ and summarized in Table $3 \mathrm{~b}$.

\subsection{Overall quality of the evidence}

Using the GRADE method [23] many outcomes were downgraded because of imprecision, mostly due to the $\mathrm{CI}$ crossing the threshold of no clinically important benefit. About half of the outcomes were downgraded for RoB. The amount of inconsistency in the results was low. There was no high-quality evidence, but moderate quality evidence was found for depression outcomes at post-treatment and follow-up (17-39 weeks) and for risk of having a diagnosis of depressive disorder at follow-up (17-39 weeks). Other evidence was of low or very low quality. 
Table 1b

Study characteristics summarized.

- The study population consisted of $62.6 \%$ females.

- The study population consisted of $66.9 \%$ Caucasian.

- Recruitment was via mental health care institutions ( $k=9)$, child and adolescent healthcare ( $k=5$ ), primary, secondary or high schools ( $k=23$ ), advertisements (for example, pamphlets, mass mailing or online advertisements; $\mathrm{k}=7$ ), alternative education for students with behavioural problems ( $\mathrm{k}=1$ ) and children's hospitals ( $\mathrm{k}=1$ )

- Studies were conducted in school ( $\mathrm{k}=16)$, a mental healthcare institution ( $\mathrm{k}=5)$, child and adolescent healthcare ( $\mathrm{k}=2)$, a university clinic $(\mathrm{k}=3)$ and at home $(\mathrm{k}=4)$; for one study the setting was unclear.

- In ten studies the use of antidepressant treatment was measured at baseline, in only one study (a third of the) participants were receiving antidepressant treatment.

- The proportion of children and adolescents with a diagnosis of MDD (based on semi-structured diagnostic interview) and dysthymic disorder was reported in six trials (with an average of $78.5 \%$ and $8.1 \%$ respectively) and four indicated prevention trials (with an average of $0.2 \%$ and $0 \%$ respectively).

- The proportion of participants with a comorbid anxiety disorder was reported in four trials (with an average of $31.5 \%$ ) and one indicated prevention trial (with an average of $17.9 \%)$

Table 2

Context and structure characteristics and overview of intervention components.

\begin{tabular}{|c|c|c|c|c|}
\hline \multicolumn{5}{|l|}{ Context and structure of CBT } \\
\hline \multicolumn{5}{|c|}{$\begin{array}{l}\text { Of the } 37 \text { CBT intervention arms, evaluated in } 31 \text { studies, } 13 \text { were treatment and } 24 \text { were indicated prevention. A total number of } 30 \text { intervention arms ( } 81.1 \% \text { ) were } \\
\text { directed at the child/adolescent only, while seven (18.9\%) were aimed at both the child/adolescent (five at adolescents and two at children) and caregiver(s). In four of } \\
\text { these seven intervention arms with caregiver involvement, caregiver sessions were given separately from the child/adolescent, while in three of the seven intervention } \\
\text { arms caregivers and children were given the sessions together. With regard to intervention format, } 22 \text { arms ( } 59.4 \% \text { ) were group CBT, } 28 \text { ( } 75.7 \% \text { ) were face-to-face and } \\
\text { seven (18.9\%) were online interventions (with no or minimal therapist support in five arms and therapist support in two arms). CBT was administered in a psychiatric } \\
\text { ( } 28.6 \%) \text { or non-psychiatric setting (for example, at school or at their own home, } 71.4 \%) \text {. The CBT interventions had a mean number of } 10.6 \text { sessions (range } 5-16 \text { ), a mean } \\
\text { duration of } 8.8 \text { weeks (range } 4-18 \text { ) and an average of } 10.06 \text { intervention hours (range } 3.5-32 \text { ) in total. Intervention intensity was rated as low in } 13 \text { out of the } 35 \\
\text { intervention arms ( } 37.1 \%) \text { and high in } 22(62.9 \%) \text {. }\end{array}$} \\
\hline \multicolumn{5}{|c|}{ Components of interventions included in the meta-regression analysis } \\
\hline Intervention name & Psychoeducation & Cognitive restructuring (challenging thoughts) & Behavioural activation & Relaxation \\
\hline 6-CDPI & No & Yes & Yes & No \\
\hline ATS & Yes & No & Yes & Yes \\
\hline ACSC & Yes & Yes & No & Yes \\
\hline BAND & Yes & Yes & Yes & Yes \\
\hline CBT (Charkandeh 2016) & NR & NR & NR & NR \\
\hline CBT (Kahn 1990) & Yes & Yes & Yes & No \\
\hline CBT (Kerfoot 2004) & Yes & Yes & Yes & NR \\
\hline CBT (Rossello 1999) & Yes & No & Yes & No \\
\hline CBT (Vostanis) & No & Yes & No & No \\
\hline CSG & Yes & NR & Yes & NR \\
\hline CTDSY & Yes & Yes & Yes & No \\
\hline Computerized CBT (Smith 2015) & No & No & Yes & Yes \\
\hline CWD-A manual adolescents & Yes & Yes & Yes & Yes \\
\hline CWD-A manual parents & Yes & Yes & Yes & Yes \\
\hline FG & Yes & NR & NR & NR \\
\hline GO & NR & Yes & Yes & NR \\
\hline MEP & No & Yes & Yes & No \\
\hline OVK & No & Yes & No & Yes \\
\hline PA & Yes & Yes & Yes & No \\
\hline PASCET & Yes & Yes & Yes & Yes \\
\hline POP & Yes & Yes & No & No \\
\hline PSL & No & No & No & No \\
\hline PST & No & Yes & Yes & No \\
\hline RAP & No & Yes & No & Yes \\
\hline SB & No & No & Yes & Yes \\
\hline SCT & Yes & Yes & No & No \\
\hline SPARX & Yes & Yes & Yes & Yes \\
\hline TADS CBT & Yes & Yes & Yes & Yes \\
\hline Total (Yes/No) & $17 / 9$ & $20 / 5$ & $19 / 7$ & $12 / 11$ \\
\hline
\end{tabular}

See Table 1a for meaning of abbreviations.

\subsection{Quantitative data synthesis}

Overall results and results of subgroups (different control conditions) are presented in Table 4 (post-treatment) and Table 5 (follow-up).

\subsubsection{Overall results}

3.5.1.1. CBT vs passive control. Low-quality evidence was found for CBT being associated with a small effect on depressive symptoms at post-treatment and at follow-up. Six trials reported low-quality evidence of CBT increasing the chance of remission by $45 \%$ and recovery by $36 \%$ at post-treatment. Low to very low-quality evidence provided inconclusive results on response, number of youths with a depressive disorder and quality of life.

\subsubsection{Subgroups results}

3.5.2.1. CBT vs waitlist/no treatment. Nineteen RCTs $(\mathrm{n}=1760)$ compared CBT with a waitlist condition [16,17,33-49]. Very low- 
Table 3a

RoB criteria score per study.

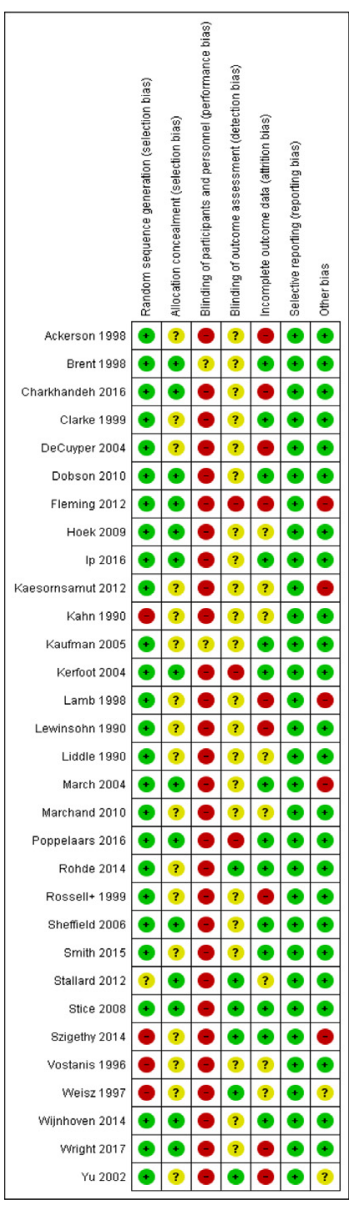

Caption: Risk of bias was rated as low (+), high (-), or unclear (?).

Table 3b

RoB criteria score summary.

Four trials (12.9\%) had high RoB for random sequence generation, while in 26 studies (83.9\%) the RoB for random sequence generation was low; in one study the sequence generation was unclear. In 14 studies (45.1\%) the RoB for allocation concealment was low, while in 17 studies (54.8\%) no method of allocation concealment was reported. In 29 studies (93.6\%) the RoB concerning the blinding of participants and personnel was high, while in two out of the 31 studies $(6.5 \%)$ the RoB was unclear. In three studies $(9.7 \%)$ the RoB for blinding of the outcome assessors was high, in six (19.4\%) low, and in $22(71.0 \%)$ it was unclear. In nine studies $(29.0 \%)$ the RoB for incomplete outcome data was high, in $14(45.2 \%)$ the RoB was low and in eight $(25.8 \%)$ it was unclear which method of handling of missing data was used. In all studies the RoB for selective outcome reporting was low. Finally, in five studies (16.1\%) there was a high RoB for other sources of bias. This high RoB was based on a conflict of interest by one of the study author(s) in three studies; in one study it was based on the fact that participants broke randomization (changed from control to intervention group or vice versa) during the implementation of the study; and in one study the high RoB was based on incomplete information about randomization, intervention and outcomes.

quality evidence was found for CBT being associated with a medium effect on depressive symptoms at post-treatment when compared to waitlist. There was moderate quality evidence for a small effect on depressive symptoms and 63\% less risk of having a depressive disorder at follow-up. Very low-quality evidence was found for CBT increasing the chance of remission by $77 \%$ and lowquality evidence for increasing the chance of recovery by $36 \%$ at post-treatment. However, low to very low-quality evidence provided inconclusive results for risk of having a depressive disorder and quality of life at post-treatment.

3.5.2.2. CBT vs attention control. Eight RCTs $(\mathrm{n}=1599)$ compared CBT with an attention control condition [50-57]. Moderate quality evidence was found for CBT being associated with a small effect on depressive symptoms when compared with attention control at post-treatment. There was low-quality evidence from two studies $(n=125)$ that CBT reduces the risk of being diagnosed with a depressive disorder by $51 \%$ at post-treatment. However, low to very low-quality evidence provided inconclusive results for remission and remission rate at post-treatment and depressive symptoms and number of youths with a depressive disorders at follow-up.

3.5.2.3. CBT vs monitoring control. Three RCTs $(n=753)$ compared CBT (administered as indicated prevention) with a monitoring control condition [58-60]. Moderate quality evidence was found for CBT being associated with no clinically important benefit on depressive symptoms when compared with monitoring control at post-treatment and at follow-up. However, confidence intervals were compatible with both an increase in effect and no clinical important benefit.

3.5.2.4. CBT vs placebo. One RCT $(\mathrm{n}=223)$ compared CBT with a placebo pill [61]. (Very) low-quality evidence provided inconclusive results for depressive symptoms, remission, response and quality of life at post-treatment.

\subsection{Meta-regression}

Significant statistical heterogeneity was detected when CBT was compared with passive control on depressive symptoms at post-treatment $\left(\mathrm{I}^{2}=81 \%\right.$ [95\% CI: $\left.\left.74-86 \%\right]\right)$ and at follow-up $\left(\mathrm{I}^{2}=68 \%\right.$ [95\% CI: 45-79\%]). To perform a meta-regression we first established the variables (Table 6) on our predefined method (see Statistical analysis in the method section of the paper). Results of the meta-regression analyses of depressive symptoms of CBT intervention components and of contextual and structural factors can be found in Tables 7 and 8 respectively.

Recipient, behavioral activation and challenging thoughts as a predictor

In the intervention component meta-regression model, selfmonitoring and social skills training were excluded, because they were significantly correlated with respectively behavioral activation ( $\rho=0.657 ; p<0.01)$ and psychoeducation $(\rho=0.425 ; p<0.05)$. In the meta-regression, behavioral activation $(b=-0.202 ; p<0.01)$ and challenging thoughts (as part of cognitive restructuring; $b=-0.312$; $p<0.05$ ) were significantly associated with a larger effect on depressive symptoms at follow-up. However, these treatment components (behavioral activation and challenging thoughts) were not significant predictors when they were analyzed individually in the meta-regression model $(b=-0.11 ; p=0.42$ for behavioral activation; $b=-0.18 ; p=0.37$ for challenging thoughts).

In the contextual and structural factors meta-regression model, the modalities face-to-face and online were excluded from the analysis because they were significantly correlated with respectively intervention dose $(\rho=0.361 ; p<0.05)$ and online sessions $(\rho=-0.693 ; p<0.01)$, and format of the CBT intervention $(\rho=-0.420 ; p<0.01)$. In the meta-regression a significant association was found between 'recipient of the intervention: child and caregiver' ( $b=-0.38 ; \mathrm{p}<0.05)$ and a larger effect on depression symptoms at follow-up, this association remained significant $(b=-0.467 ; \mathrm{p}<0.05)$ when analyzed individually in a regression model. 
Table 4

Post-treatment outcomes CBT versus passive control.

\begin{tabular}{|c|c|c|c|c|c|c|c|}
\hline Outcome & (Sub-)analysis & Trials (reference) & $\mathrm{N}$ & Effect Size & {$[95 \% \mathrm{CI}]$} & Heterogeneity $\left(\mathrm{I}^{2}(95 \% \mathrm{CI})\right)$ & Quality (GRADE) \\
\hline \multirow[t]{5}{*}{ Depression } & Total & 26 & 2951 & SMD $=-0.41$ & {$[-0.56,-0.27]$} & $81 \%(74-86 \%)$ & Low $^{b}$ \\
\hline & WL & 18 & 1556 & $\mathrm{SMD}=-0.62$ & {$[-0.84,-0.39]$} & $84 \%(76-88 \%)$ & Very Low ${ }^{\text {a b }}$ \\
\hline & Attention control & 4 & 453 & $\mathrm{SMD}=-0.20$ & {$[-0.33,-0.06]$} & $13 \%(0-72 \%)$ & Moderate ${ }^{d}$ \\
\hline & Monitoring control & 3 & 719 & $\mathrm{SMD}=-0.14$ & {$[-0.32,0.04]$} & $28 \%(0-71 \%)$ & Moderate $^{d}$ \\
\hline & Placebo & 1 & 223 & $\mathrm{SMD}=0.04$ & {$[-0.17,0.25]$} & $\mathrm{N} / \mathrm{A}$ & Very Low a d \\
\hline \multirow[t]{4}{*}{ Remission rate } & Total & 5 & 587 & $R R=0.55$ & {$[0.31,0.97]$} & $80 \%(35-90 \%)$ & $\operatorname{Low}^{\text {a b }}$ \\
\hline & WL & 2 & 75 & $\mathrm{RR}=0.23$ & {$[0.13,0.40]$} & $0 \%\left(\mathrm{~N} / \mathrm{A}^{*}\right)$ & Very Low ${ }^{\text {a d }}$ \\
\hline & Attention control & 2 & 289 & $\mathrm{RR}=0.73$ & {$[0.46,1.14]$} & $59 \%\left(\mathrm{~N} / \mathrm{A}^{*}\right)$ & Low ${ }^{\text {b d }}$ \\
\hline & Placebo & 1 & 223 & $\mathrm{RR}=1.04$ & {$[0.58,1.88]$} & $\mathrm{N} / \mathrm{A}$ & Low $^{\text {a d }}$ \\
\hline \multirow[t]{2}{*}{ Response rate } & Total & 1 & 176 & $R R=0.80$ & {$[0.61,1.05]$} & N/A & $\operatorname{Low}^{\text {a d }}$ \\
\hline & Placebo & 1 & 176 & $\mathrm{RR}=0.80$ & {$[0.61,1.05]$} & $\mathrm{N} / \mathrm{A}$ & Low $^{\text {a d }}$ \\
\hline \multirow[t]{4}{*}{ Number depressed } & Total & 4 & 398 & $R R=0.70$ & $0.70[0.42,1.16]$ & $62 \%(0-85 \%)$ & Very Low ${ }^{\text {a b d }}$ \\
\hline & WL & 1 & 50 & $\mathrm{RR}=1.15$ & {$[0.38,3.51]$} & N/A & Very Low a d \\
\hline & Attention control & 2 & 125 & $\mathrm{RR}=0.49$ & {$[0.31,0.76]$} & $0 \%\left(N / A^{*}\right)$ & Low ${ }^{\text {a d }}$ \\
\hline & Placebo & 1 & 223 & $\mathrm{RR}=1.01$ & {$[0.73,1.40]$} & $\mathrm{N} / \mathrm{A}$ & Low $^{\text {a d }}$ \\
\hline \multirow[t]{2}{*}{ Recovery } & Total & 1 (2 arms) & 96 & $R R=0.64$ & {$[0.42,0.98]$} & $0 \%(\mathrm{~N} / \mathrm{A})$ & Low $^{d}$ \\
\hline & WL & 1 (2 arms) & 96 & $\mathrm{RR}=0.64$ & {$[0.42,0.98]$} & $0 \%\left(\mathrm{~N} / \mathrm{A}^{*}\right)$ & Low $^{d}$ \\
\hline \multirow[t]{2}{*}{ Quality of life } & Total & 1 & 182 & SMD $=0.08$ & {$[-0.21,0.37]$} & N/A & Very Low $^{\text {a d }}$ \\
\hline & Placebo & 1 & 182 & $\mathrm{SMD}=0.08$ & {$[-0.21,0.37]$} & $\mathrm{N} / \mathrm{A}$ & Very Low $^{\text {a d }}$ \\
\hline
\end{tabular}

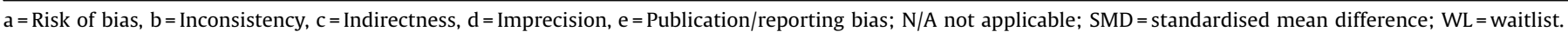

${ }^{*}$ A minimum number of 3 trials was necessary for the $95 \% \mathrm{CI}$ calculation of the heterogeneity statistic.

Table 5

Follow-up outcomes CBT versus passive control.

\begin{tabular}{|c|c|c|c|c|c|c|c|}
\hline Outcome & (Sub-) analysis & Trials (reference) & $\mathrm{N}$ & Effect Size & {$[95 \% \mathrm{CI}]$} & Heterogeneity $\left(\mathrm{I}^{2}(95 \% \mathrm{CI})\right)$ & Quality (GRADE) \\
\hline \multirow[t]{4}{*}{ Depression } & Total & 15 & 2674 & SMD $=-0.20$ & {$[-0.33,-0.07]$} & $68 \%(45-79 \%)$ & Low $^{\text {b d }}$ \\
\hline & WL & 7 & 888 & $\mathrm{SMD}=-0.40$ & {$[-0.62,-0.18]$} & $67 \%(7-83 \%)$ & Moderate ${ }^{\text {b }}$ \\
\hline & Attention control & 5 & 1067 & $\mathrm{SMD}=-0.05$ & {$[-0.25,0.16]$} & $61 \%(0-83 \%)$ & Low $^{\text {b d }}$ \\
\hline & Monitoring control & 3 & 719 & $\mathrm{SMD}=-0.14$ & {$[-0.28,0.01]$} & $3 \%(0-62 \%)$ & Moderate $^{d}$ \\
\hline \multirow[t]{3}{*}{ Number depressed } & Total & 3 & 448 & $\mathbf{R R}=\mathbf{0 . 7 2}$ & {$[0.41,1.28]$} & $46 \%(0-81 \%)$ & Low a d \\
\hline & $\mathrm{WL}$ & 1 (2 arms) & 337 & $\mathrm{RR}=0.37$ & {$[0.15,0.92]$} & $15 \%\left(N / A^{*}\right)$ & Moderate $^{d}$ \\
\hline & Attention control & 2 & 111 & $\mathrm{RR}=0.98$ & {$[0.67,1.44]$} & $0 \%\left(\mathrm{~N} / \mathrm{A}^{*}\right)$ & Very Low ${ }^{\text {a d }}$ \\
\hline
\end{tabular}

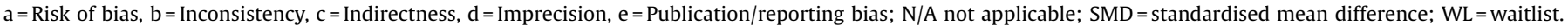

${ }^{*}$ A minimum number of 3 trials was necessary for the $95 \% \mathrm{CI}$ calculation of the heterogeneity statistic.

Table 6

Included variables.

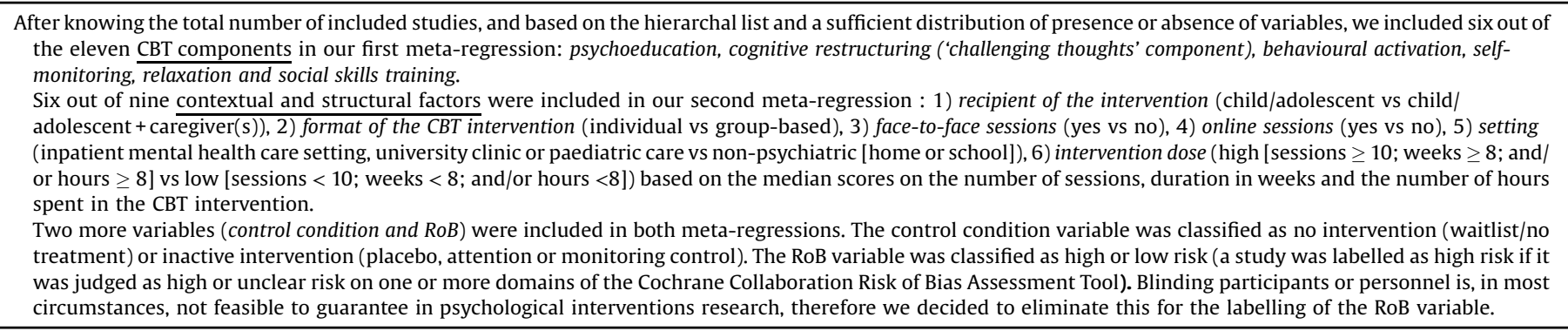

\section{Discussion}

This comprehensive systematic review and meta-analysis (31 studies; 4335 participants) explored the overall effects of CBT interventions on depression in youth and is the first study that focuses on the question of whether certain combinations or lack of CBT components, and contextual and structural factors, can be identified that moderate the effects. Moreover, the specific characteristics of the CBT components were rated on a detailed level so differences between CBT interventions on components could be examined. Our results suggest that CBT is effective for youth in reducing depressive symptoms immediately after the end of treatment $(S M D=-0.41)$ and at follow-up (17-39 weeks; SMD = $-0.20)$. Also, a child/adolescent with subclinical depressive symptoms who receives CBT as indicated prevention has 63\% less risk of having a depressive disorder at follow-up. Other results of our analyses showed that after receiving CBT, youth with depression have $45 \%$ more chance of being in remission and $36 \%$ more chance of recovery compared with control groups, but the quality of the evidence is less robust. 
Table 7

Meta-regression analysis intervention components.

\begin{tabular}{|c|c|c|c|c|c|c|c|c|}
\hline \multirow[b]{2}{*}{ Variable name } & \multicolumn{4}{|c|}{ Multivariate regression model $^{\mathrm{a}}$} & \multicolumn{4}{|c|}{ Univariate regression model } \\
\hline & $\mathrm{N}$ & $\mathrm{B}$ & SE & $\mathrm{P}$ & $\mathrm{N}$ & $\mathrm{B}$ & SE & $\mathrm{p}$ \\
\hline \multicolumn{9}{|l|}{ Depression post-treatment outcome } \\
\hline Control group & 33 & 0.492 & 0.159 & 0.002 & 33 & 0.492 & 0.159 & 0.002 \\
\hline Psychoeducation & 27 & 0.073 & 0.124 & 0.558 & 31 & -0.092 & 0.154 & 0.551 \\
\hline Cognitive restructuring (challenging thoughts) & 29 & -0.116 & 0.170 & 0.497 & 29 & 0.075 & 0.225 & 0.737 \\
\hline Activation & 30 & -0.237 & 0.125 & 0.058 & 30 & -0.219 & 0.164 & 0.182 \\
\hline Relaxation & 27 & -0.070 & 0.113 & 0.538 & 27 & -0.091 & 0.158 & 0.565 \\
\hline Risk of bias & 27 & -0.158 & 0.291 & 0.587 & 33 & -0.033 & 0.342 & 0.942 \\
\hline \multicolumn{9}{|l|}{ Depression follow-up outcome } \\
\hline Control group & 18 & 0.402 & 0.084 & 0.000 & 19 & 0.321 & 0.113 & 0.004 \\
\hline Psychoeducation & 18 & 0.199 & 0.112 & 0.076 & 18 & -0.092 & 0.144 & 0.522 \\
\hline Cognitive restructuring (challenging thoughts) & 18 & -0.312 & 0.120 & 0.010 & 18 & -0.176 & 0.194 & 0.365 \\
\hline Activation & 18 & -0.202 & 0.071 & 0.005 & 18 & -0.109 & 0.134 & 0.415 \\
\hline Relaxation & 17 & -0.070 & 0.097 & 0.470 & 17 & 0.137 & 0.141 & 0.330 \\
\hline Risk of bias & 17 & -0.332 & 0.218 & 0.128 & 17 & 0.225 & 0.192 & 0.242 \\
\hline
\end{tabular}

${ }^{\text {a }}$ Measuring variable within a regression model including all variables.

Table 8

Meta-regression analysis contextual and structural factors.

\begin{tabular}{|c|c|c|c|c|c|c|c|c|}
\hline \multirow[b]{2}{*}{ Variable name } & \multicolumn{4}{|c|}{ Multivariate regression model ${ }^{\mathrm{a}}$} & \multicolumn{4}{|c|}{ Univariate regression model } \\
\hline & $\mathrm{N}$ & $\mathrm{B}$ & SE & $\mathrm{P}$ & $\mathrm{N}$ & B & SE & $\mathrm{p}$ \\
\hline \multicolumn{9}{|l|}{ Depression post-treatment outcome } \\
\hline Control group & 33 & 0.492 & 0.159 & 0.002 & 33 & 0.492 & 0.159 & 0.002 \\
\hline $\begin{array}{l}\text { Recipient (child/adolescent vs } \\
\text { child/adolescent + caregiver) }\end{array}$ & 33 & -0.089 & 0.106 & 0.403 & 33 & -0.132 & 0.120 & 0.269 \\
\hline $\begin{array}{l}\text { Intervention format } \\
\text { (individual vs group-based) }\end{array}$ & 33 & 0.164 & 0.162 & 0.310 & 33 & 0.000 & 0.179 & 0.999 \\
\hline $\begin{array}{l}\text { Setting } \\
\quad \text { (psychiatric vs non-psychiatric) }\end{array}$ & 33 & -0.151 & 0.148 & 0.307 & 33 & -0.157 & 0.166 & 0.344 \\
\hline Intervention intensity (high vs low) & 31 & -0.097 & 0.182 & 0.595 & 31 & -0.035 & 0,203 & 0.864 \\
\hline ROB & 31 & 0.102 & 0.424 & 0.810 & 33 & -0.033 & 0.342 & 0.942 \\
\hline \multicolumn{9}{|l|}{ Depression follow-up outcome } \\
\hline Control group & 19 & 0.275 & 0.110 & 0.012 & 19 & 0.321 & 0.113 & 0.004 \\
\hline $\begin{array}{l}\text { Recipient (child/adolescent vs } \\
\text { child/adolescent + caregiver) }\end{array}$ & 19 & -0.380 & 0.184 & 0.038 & 19 & -0.467 & 0.191 & 0.014 \\
\hline $\begin{array}{l}\text { Intervention format } \\
\text { (individual vs group-based) }\end{array}$ & 17 & 0.079 & 0.136 & 0.558 & 19 & -0.063 & 0.133 & 0.634 \\
\hline $\begin{array}{l}\text { Setting } \\
\quad \text { (psychiatric vs non-psychiatric) }\end{array}$ & 17 & -0.069 & 0.332 & 0.836 & 19 & 0.285 & 0.264 & 0.281 \\
\hline Intervention intensity (high vs low) & 17 & 0.145 & 0.119 & 0.223 & 17 & 0.073 & 0.143 & 0.611 \\
\hline ROB & 19 & -0.066 & 0.268 & 0.805 & 19 & 0.225 & 0.192 & 0.242 \\
\hline
\end{tabular}

${ }^{a}$ Measuring variable within a regression model including all variables.

Despite these positive results, effects in terms of symptom reduction are small and have limited clinical importance when CBT (administered as indicated prevention) was compared with monitoring as control condition. Still, our results indicate that there might be room to improve the effects of CBT on the longterm, which is important because the recurrence of depression in youth is high [7]. Results of our meta-regression showed a correlation between improvement on depression outcomes and the combination of the components behavioral activation and challenging thoughts (as part of cognitive restructuring) in a CBT intervention. We also found an association between more favorable treatment outcomes and caregiver(s) involvement in the intervention. Post-hoc sensitivity analysis indicated that this effect was especially beneficial for children younger than 12 . For the other two CBT components (psychoeducation and relaxation) and three contextual and structural factors (format of the intervention, setting and intervention dose), no significant correlation with more favorable outcomes were found. Another important variable we included, which was not related to the intervention but to the research, was the quality of the studies
(RoB). The quality of the studies did not have a moderating effect in our analysis. This might be due to the fact that we did not take dimensional aspects into account and worked with a cut-off point. As a last point we analyzed post-hoc if moderator effects might be influenced due to the intervention being treatment or indicated prevention. First of all we found only small differences between effects of indicated prevention and treatment on depression symptoms at follow-up. Secondly, when the distribution of moderators was analyzed, only the moderators psycho-education, psychiatric setting and high treatment intensity were significantly more prevalent in treatment trials. As those moderators had no significant influence on the primary outcomes, we concluded that moderating effects were not explained by intervention type (treatment or indicated prevention).

\subsection{Our results in relation to other evidence}

Recent reviews used inclusion criteria that were more stringent than the inclusion criteria we used in our review, for example regarding specific age groups (only children $[11,20]$ or adolescents 
[62]), specific types of preventive psychological therapy [10] or a different range of severity of depression. However, our overall results were in line with their outcomes such as non-significant or small effects on depressive symptoms and a decreasing effect as follow-up time progresses. Moderating variables have also been investigated in other research and meta-analyses, with some associations confirming or contradicting our results.

A recent meta-analysis found that the component behavioral activation is effective for young people with depression [63]. This corresponds with another study in which the views of children and adolescents were analyzed. Children and adolescents identified behavioral activation and challenging thoughts as an achievable and effective strategy in reducing depressive symptoms, while $65 \%$ of other components of CBT were not judged to be effective [32]. Results of our meta-regression analyses correspond with these results.

With respect to caregiver involvement there are conflicting results between other reviews (and ours). In contrast to our results, one review found that CBT for children (aged 7-13 years) with depression without caregiver involvement was significantly more effective than with caregiver involvement [11]. Two other reviews found no differences between involving a caregiver and not involving them when treating youth with depression and/or anxiety with CBT [64] and computerized CBT [65]. In line with our results, a review focusing on all types of psychotherapy for youth (mean age of $12(\mathrm{SD}=3.3)$ ) with depression; the authors concluded that caregiver participation was associated with improved treatment outcomes [19]. These differences in effect of caregiver involvement might be explained by the way caregivers were involved. In the field of anxiety disorders, for example, an individual patient data meta-analysis did not find any additional benefit of caregiver involvement in general, but exploratory analyses showed that if CBT focused on contingency management (rewarding desirable behavior and ignoring unwanted behavior) or transfer of control (the process of transferring skills from the therapist to the caregiver) better outcomes were observed at follow-up [66]. In our analysis, there were not enough studies to differentiate between the type of caregiver involvement. However, reviewing the studies with caregiver involvement, we do see differences for example, some interventions were delivered to the caregiver and child/adolescent simultaneously while others were delivered separately. In some interventions contingency management was used, while others did not use this.

Regarding intervention intensity, we did not find an association with an effect on depression symptoms, which is in accordance with Yang et al. [11 ]. In contrast, Arnberg et al. concluded that more sessions (amount of sessions multiplied by the session duration in minutes) leads to a larger effect [20].

Although we did not find positive influence of psychoeducation and could not include goalsetting in our analysis, there is evidence that the combination of these in a brief psychosocial interventions can be as effective as a CBT intervention [67]. So even if our results don't show the added benefit of a component, it does not mean it does not contribute to an improved effect.

\subsection{Strengths and limitations}

A specific advantage of our review is that it is the first to investigate the components of different CBT protocols in detail, thereby continuing the work of Fréchette-Simard et al. [15]. As they suggested, we extracted information directly from the individual intervention protocols, rather than from the articles in which the studies were reported. This approach allowed us to obtain more detailed information about the intervention components. Another strength of our analysis is that the meta-regression gave insight into two CBT components and caregiver involvement being positively associated with improvement of effects of CBT.

Due to our decision to try and limit the heterogeneity that would be caused by active comparison groups (including treatment as usual), our review is limited by the number of studies included. And although we were able to perform a metaregression analysis, we were limited by the number of variables we could include to keep sufficient statistical power and by the insufficient distribution of the presence or absence of variables between studies. Consequently, we could not include other important CBT components (for example, other elements of cognitive restructuring, positive reinforcement, goalsetting, relapse prevention), and contextual and structural factors (for example, indicated prevention/treatment, age or severity of the depression) in our meta-regression. Two limits to the outcome of the meta-regression should be made. First, The significant moderating effects of CBT components were only indicated in the multivariate regression model. This demonstrates that the activation and challenging thoughts components of CBT are effective as a combination, while there is no evidence for added benefit as stand-alone components. And secondly, recipient of the CBT intervention, which was a significant moderator for the depression outcomes at follow-up, only had one study of the 15 which targeted both children and caregivers. Another limitation is the high number of studies with a small sample size and/or studies at high RoB in the waitlist/no treatment subgroup. These aspects caused inconsistent results and made the depression outcome less robust at post-treatment. This is unfortunate because due to the number of included participants it could have created a precise result, which could have made us more confident of the true effect. Furthermore, we could not obtain some of the original intervention protocols, so we did not have detailed information on all included CBT interventions. Details were also missing about treatment protocol adherence and thereby it is unclear in how many cases the components were truly delivered by the therapist. Finally, there was an underrepresentation of studies conducted in children $(\mathrm{k}=5)$ versus adolescents $(\mathrm{k}=25)$.

\subsection{Implications for practice}

Based on our findings and other research, CBT that includes behavioral activation and a challenging thoughts component (as part of cognitive restructuring) might improve outcomes for youth in the long-term. However, it is premature to suggest that practice must only apply CBT that includes these two core components. More evidence is needed to provide a causal relationship between these components and improved outcomes.

The results seem to suggest that when treating youth with CBT that the involvement of caregivers might improve depression symptoms on the long term, this might be due to several reasons. First, an etiological factor in the development of depression is the quality of the attachment relationship [68,69]. Although CBT does not target improvement of the attachment relationship directly, children learn to increase adaptive coping strategies and caregivers show their commitment by being involved in the intervention. These factors could improve the quality of the attachment relationship and might help to improve outcomes. Second, for children the possibility of transfer of control (caregiver involvement can lead to the transfer of information and skills to the child) might lead to higher intervention fidelity and might make the child more aware of the therapeutic process between the sessions. A metaanalysis of CBT treatment in children has already showed that CBT focused on transfer of control leads to long-term maintenance of treatment gains [66]. Actively involving caregiver(s) in the therapeutic process at the same time by use of contingency 
management may also lead to improved effects [66]. Furthermore, for the child/adolescent, caregiver involvement might lead to more consistency in their interactions with their therapist, because youth are more inclined to follow the sessions when caregivers are involved $[70,71]$.

\subsection{Directions for future research}

The results of our review provides additional evidence and should give an impulse for more research into uncovering the working mechanisms of CBT, which has been strongly recommended to be the next step in improving psychological interventions [14]. Therefore, head-to-head RCTs should be undertaken with intervention arms consisting of CBT with and without the intervention components (and a combination of these components), and contextual and structural factors (especially, different types of (non) parental involvement) in order to replicate our results in a 'real world' setting. However, when viewing the overall evidence, in general more RCTs should be undertaken to improve the quality of the total evidence, which is currently moderate at best. In particular, it is important to investigate the effects of CBT on children with clinical depression, because this is an underresearched area.

Several aspects could not be analyzed in our meta-analysis. It would be very informative to further investigate the influence of these aspects such as other components and structural characteristics on outcomes. Clinically relevant topics to be investigated are the optimal sequencing and intensity of CBT components during the intervention, and how to improve or sustain long-term outcomes by the application of booster sessions or continuing CBT after remission has started, which has been advised for adults $[72,73]$.

Finally, there have been several attempts to provide evidence on improving the effects of CBT, yet none have been fully successful in separating out the effectiveness of specific CBT components. A possibility for future research is to conduct an individual patient data meta-analysis (IPDMA) because this method can increase power and reliability, as well as enabling an examination of the differential effectiveness of CBT and its components among specific subgroups across studies [74]. Most importantly, IPDMA allows for analyzing the predictive value of specific (baseline) characteristics and intervention components [74].

\section{Conflict of interest}

All other authors have no competing interests. The views of the authors expressed in this paper do not necessarily reflect the views of NCCMH, Royal College of Psychiatrists, Trimbos Institute or NHS England.

\section{Role of funding source}

Funding for this study was provided by a grant from ZonMw (Dossier number: 70-72900-98-15101) had no role in the study design, collection, analysis or interpretation of the data, writing the manuscript, or the decision to submit the paper for publication.

\section{Appendix A. Supplementary data}

Supplementary material related to this article can be found, in the online version, at doi:https://doi.org/10.1016/j.eurpsy.2018.12.008.

\section{References}

[1] Costello EJ, Erkanli A, Angold A. Is there an epidemic of child or adolescent depression? J Child Psychol Psychiatry 2006;47(Dec. (12))1263-71. . [Internet]
Available from http://search.ebscohost com/login.aspx? direct=true \&db=psyh\&AN=2006-22157-009\&site=ehost-live.

[2] Thapar A, Collishaw S, Pine DS, Thapar AK. Depression in adolescence. Lancet 2012;379(9820)1056-67, doi:http://dx.doi.org/10.1016/S0140-6736(11) 60871-4 [Internet], Available from:.

[3] Murray CJL. The state of US health, 1990-2010. JAMA 2013;310(6)591, doi: http://dx.doi.org/10.1001/jama.2013.13805 [Internet], Available from.

[4] Harrington R. Depression, suicide and deliberate self-harm in adolescence. $\mathrm{Br}$ Med Bull Oxf Acad 2001;(December):47-60.

[5] Chassin L, Beltran I, Lee M, Haller M, Villalta I. Vulnerability to substance use disorders in childhood and adolescence. In: Ingram R, Price J, editors. Vulnerability to psychopathology: risk across the lifespan. New York: Guilford Press; 2001. p. 107-34.

[6] Smit E, Bohlmeijer E, Cuijpers P. Wetenschappelijke onderbouwing depressiepreventie. Epidemiologie, aangrijpingspunten, huidige praktijk, nieuwe richtingen Utrecht. 2003.

[7] Curry J, Silva S, Rohde P, Ginsburg G, Kratochvil C, Simons A, et al. Recovery and recurrence following treatment for adolescent major depression. Arch Gen Psychiatry 2011;68(Mar (3))263-70. . [Internet], Available from http://search. ebscohost.com/login.aspx?direct=true \&db=psyh\&AN=2011-07732007\&site $=$ ehost-live.

[8] Cipriani A, Zhou X, Del Giovane C, Hetrick SE, Qin B, et al. Comparative efficacy and tolerability of antidepressants for major depressive disorder in children and adolescents: a network meta-analysis. Lancet 2016;388(10047)881-90, doi:http://dx.doi.org/10.1016/S0140-6736(16)30385-3 Available from.

[9] Murray J, Cartwright-Hatton S. NICE guidelines on treatment of depression in childhood and adolescence: implications from a CBT perspective. Behav Cogn Psychother 2006;34(Feb (02))129. . [cited 2017 Dec 27], Available from http:// www.journals.cambridge.org/abstract_S1352465805002742.

[10] Hetrick SE, Cox GR, Witt KG, Bir JJ, Merry SN. Cognitive behavioural therapy (CBT), third-wave CBT and interpersonal therapy (IPT) based interventions for preventing depression in children and adolescents. Cochrane Database Syst Rev 2016(Aug) (1469-493X (Electronic)):CD003380.

[11] Yang L, Zhou X, Zhou C, Zhang Y, Pu J, Liu L, et al. Efficacy and acceptability of cognitive behavioral therapy for depression in children: a systematic review and meta-analysis. Acad Pediatr 2016;17(1):1.

[12] Klein JB, Jacobs RH, Reinecke MA. Cognitive-behavioral therapy for adolescent depression: a meta-analytic investigation of changes in effect-size estimates. J Am Acad Child Adolesc Psychiatry 2007;46(Nov (11))1403-13. . Available from http://search.ebscohost.com/login.aspx?direct=true\&db=psyh\&AN=200716584-002\&site=ehost-live.

[13] Weisz JR, Kuppens S, Ng MY, Eckshtain D, Ugueto AM, et al. What five decades of research tells us about the effects of youth psychological therapy: a multilevel meta-analysis and implications for science and practice. Am Psychol 2017;72(2):79-117.

[14] Holmes EA, Ghaderi A, Harmer CJ, Ramchandani PG, Cuijpers P, Morrison AP, et al. The Lancet Psychiatry Commission on psychological treatments research in tomorrow's science. Lancet Psychiatry 2018;5(3):237-86.

[15] Fréchette-Simard C, Plante I, Bluteau J. Strategies included in cognitive behavioral therapy programs to treat internalized disorders: a systematic review. Cogn Behav Ther 2017;6073(December)1-23, doi:http://dx.doi.org/ 10.1080/16506073.2017.1388275 [Internet], Available from.

[16] Sheffield JK, Spence SH, Rapee RM, Kowalenko N, Wignall A, Davis A, et al. Evaluation of universal, indicated, and combined cognitive-behavioral approaches to the prevention of depression among adolescents. J Consult Clin Psychol 2006;74(1)66-79. . [Internet], Available from http://search.ebscohost. $\mathrm{com} /$ login.aspx?direct=true \&db=psyh\&AN=2006-03253-007\&site=ehost-live

[17] Wijnhoven LAMW, Creemers DHM, Vermulst AA, Scholte RHJ, Engels RCME. Randomized controlled trial testing the effectiveness of a depression prevention program ('Op Volle Kracht') among adolescent girls with elevated depressive symptoms. J Abnorm Child Psychol 2014;42(Feb (2))217-28. [Internet], Available from http://search.ebscohost.com/login.aspx? direct=true $\& \mathrm{db}=$ psyh \&AN=2013-27298-001\&site=ehost-live.

[18] Weersing VR, Rozenman M, Gonzalez A. Core components of therapy in youth: do we know what to disseminate? Behav Modif 2009;33(Jan (1)):24-47.

[19] Dowell KA, Ogles BM. The effects of parent participation on child psychotherapy outcome: a meta-analytic review. J Clin Child Adolesc Psychol 2010;39(2):151-62.

[20] Arnberg A, Ost L. CBT for children with depressive symptoms: a meta-analysis. Cogn Behav Ther 2014;43(Oct (4))275-88. . Available from http://search. ebscohost.com/login.aspx?direct=true \&db=psyh\&AN=2014-49266002\&site=ehost-live.

[21] Moher D, Liberati A, Tetzlaff J, Altman DG. Reprint - preferred reporting items for systematic reviews and meta-analyses: the PRISMA statement. Phys Ther 2009;89(9):873-80.

[22] Higgins JPT, Green S, Cochrane Collaboration. Cochrane handbook for systematic reviews of interventions. NJ: Wiley-Blackwell; 2008.

[23] Guyatt GH, Oxman AD, Schünemann HJ, Tugwell P, Knottnerus A. GRADE guidelines: a new series of articles in the Journal of Clinical Epidemiology. J Clin Epidemiol 2011;64(4):380-2.

[24] Chorpita BF, Becker KD, Daleiden EL. Understanding the common elements of evidence-based practice: misconceptions and clinical examples. J Am Acad Child Adolesc Psychiatry 2007;46(May):647-52.

[25] Chorpita BF, WJR. Modular approach to therapy for children with anxiety, depression, trauma, or conduct problems (MATCH-ADTC). Satellite Beach, FL: PracticeWise, LLC; 2009. 
[26] Chorpita BF, Daleiden EL. Mapping evidence-based treatments for children and adolescents: application of the distillation and matching model to 615 treatments from 322 randomized trials. J Consult Clin Psychol 2009;77(3):566-79.

[27] The Nordic Cochrane Centre (The Cochrane Collaboration). Review manager (RevMan) version 5.3. Copenhagen; 2014.

[28] Cohen J. Statistical power analysis for the behavioral sciences. Hillsdale, New Jersey: Erlbaum Associates; 1988. p. 400.

[29] Higgins JPT, Thompson SG, Deeks JJ, Altman DG. Measuring inconsistency in meta-analyses. BMJ Br Med J 2003;327(7414):557-60.

[30] StataCorp. Stata statistical software: release 12. College Station, TX: StataCorp LP; 2011.

[31] Thompson SG, Higgins JPT. How should meta-regression analyses be undertaken and interpreted? Stat Med 2002;21(11):1559-73.

[32] Ng MY, Eckshtain D, Weisz JR. Assessing fit between evidence-based psychotherapies for youth depression and real-life coping in early adolescence. J Clin Child Adolesc Psychol 2016;45(6):732-48.

[33] Ackerson J, Scogin F, McKendree-Smith N, Lyman RD. Cognitive bibliotherapy for mild and moderate adolescent depressive symptomatology. J Consult Clin Psychol 1998;66(Aug)685-90 0022-006X (Print).

[34] Kahn JS, Kehle TJ, Jenson WR, Clark E. Comparison of cognitive-behavioral, relaxation, and self-modeling interventions for depression among middleschool students. School Psychol Rev 1990;19(2)196-211. . [Internet], Available from http://search.ebscohost.com/login.aspx? direct=true \&db=psyh\&AN=1990-26044-001\&site=ehost-live.

[35] Kerfoot M, Harrington R, Harrington V, Rogers J, Verduyn C. A step too far? Randomized trial of cognitive-behaviour therapy delivered by social workers to depressed adolescents. Eur Child Adolesc Psychiatry 2004;13(Apr (2))92-9. [Internet], Available from http://search.ebscohost.com/login.aspx? direct $=$ true \&db=psyh\&AN=2004-95107-005\&site=ehost-live.

[36] Lamb JM, Puskar KR, Sereika SM, Corcoran M. School-based intervention to promote coping in rural teens. MCN Am J Matern Child Nurs 1998;23(Jul)18794 0361-929X (Print).

[37] Liddle B, Spence SH. Cognitive-behaviour therapy with depressed primary school children: a cautionary note. Behav Psychother 1990;18(Apr (2))85-102. . [nternet], Available from http://search.ebscohost.com/login.aspx? direct $=$ true \&db=psyh\&AN=1990-28967-001\&site=ehost-live.

[38] Rosselló J, Bernal G. The efficacy of cognitive-behavioral and interpersonal treatments for depression in Puerto Rican adolescents. J Consult Clin Psycho 1999;67(Oct (5))734-45. . [Internet], Available from http://search.ebscohost. com/login.aspx?direct=true \&db=psyh\&AN=1999-11785-012\&site=ehost-live.

[39] Smith P, Scott R, Eshkevari E, Jatta F, Leigh E, Harris V, et al. Computerised CBT for depressed adolescents: randomised controlled trial. Behav Res Ther 2015;73(Oct)104-10. . [Internet], Available from http://search.ebscohost.com/ login.aspx?direct=true\&db=psyh\&AN=2015-43144-016\&site=ehost-live.

[40] Weisz JR, Thurber CA, Sweeney L, Proffitt VD, LeGagnoux GL. Brief treatment of mild-to-moderate child depression using primary and secondary control enhancement training. J Consult Clin Psychol 1997;65(Aug (4))703-7. . [Internet], Available from http://search.ebscohost.com/login.aspx? direct=true\&db=psyh\&AN=1997-06864-021\&site=ehost-live.

[41] Yu DL, Seligman MEP. Preventing depressive symptoms in Chinese children. Prev Treat 2002;5(May (1)). . [Internet], Available from http://search. ebscohost.com/login.aspx?direct=true \&db=psyh\&AN=2002-14077$002 \&$ site $=$ ehost-live.

[42] Charkhandeh M, Talib MA, Hunt CJ. The clinical effectiveness of cognitive behavior therapy and an alternative medicine approach in reducing symptoms of depression in adolescents. Psychiatry Res 2016;239:325-30. . [Internet]. Available from http://www.embase.com/search/results? subaction=viewrecord\&from=export\&id=L609457997.

[43] Lewinsohn PM, Clarke GN, Hops H, Andrews J. Cognitive-behavioral treatment for depressed adolescents. Behav Ther 1990;21(4)385-401. . [Internet], Available from http://www.embase.com/search/results? subaction=viewrecord\&from=export\&id=L21003689.

[44] Clarke GN, Rohde P, Lewinsohn PM, Hops H, Seeley JR. Cognitive-behavioral treatment of adolescent depression: efficacy of acute group treatment and booster sessions. J Am Acad Child Adolesc Psychiatry 1999;38(Mar (3))272-9. [Internet], Available from http://search.ebscohost.com/login.aspx? direct=true \&db=psyh\&AN=1999-10534-011\&site=ehost-live.

[45] De Cuyper S, Timbremont B, Braet C, De Backer V, et al. Treating depressive symptoms in schoolchildren: a pilot study. Eur Child Adolesc Psychiatry 2004;13(Apr (2))105-14. . [Internet], Available from http://search.ebscohost. com/login.aspx?direct=true \&db=psyh\&AN=2004-95107-007\&site=ehost-live.

[46] Fleming T, Dixon R, Frampton C, Merry S. A pragmatic randomized controlled trial of computerized CBT (SPARX) for symptoms of depression among adolescents excluded from mainstream education. Behav Cogn Psychother 2012;40(Oct (5))529-41. . [Internet], Available from http://search.ebscohost. $\mathrm{com} /$ login .aspx?direct=true\&db=psyh\&AN=2012-24762-003\&site=ehost-live.

[47] Stice E, Rohde P, Seeley JR, Gau JM. Brief cognitive-behavioral depression prevention program for high-risk adolescents outperforms two alternative interventions: a randomized efficacy trial. J Consult Clin Psychol 2008;76(Aug (4))595-606. . [Internet], Available from http://search.ebscohost.com/login. aspx?direct=true $\& \mathrm{db}=\mathrm{psyh} \& \mathrm{AN}=2008-09736-006 \&$ site=ehost-live.

[48] Hoek W, Schuurmans J, Koot HM, Cuijpers P. Prevention of depression and anxiety in adolescents: a randomized controlled trial testing the efficacy and mechanisms of Internet-based self-help problem-solving therapy. Trials 2009;10:93 1745-6215 (Electronic).
[49] Kaesornsamut P, Sitthimongkol Y, Williams RA, Sangon S, Rohitsuk W, Vorapongsathron T. Effectiveness of the BAND intervention program on tha adolescents' sense of belonging, negative thinking and depressive symptoms. Pacific Rim Int J Nurs Res 2012;16(Jan (1))29-47. . [Internet], Available from http://search.ebscohost.com/login.aspx? direct=true $\& \mathrm{db}=\mathrm{cin} 20 \& \mathrm{AN}=104560140 \&$ site $=$ ehost-live.

[50] Brent DA, Kolko DJ, Birmaher B, Baugher M, Bridge J, Roth C, et al. Predictors of treatment efficacy in a clinical trial of three psychosocial treatments for adolescent depression. J Am Acad Child Adolesc Psychiatry 1998;37(Sep (9)) 906-14. . [Internet], Available from http://search.ebscohost.com/login.aspx? direct=true $\& \mathrm{db}=\mathrm{psyh} \& \mathrm{AN}=1998-10896-008 \&$ site $=$ ehost-live.

[51] Dobson KS, Hopkins JA, Fata L, Scherrer M, Allan LC. The prevention of depression and anxiety in a sample of high-risk adolescents: a randomized controlled trial. Can J Sch Psychol 2010;25(Dec (4))291-310. . [Internet], Available from http://search.ebscohost.com/login.aspx? direct $=$ true $\& \mathrm{db}=\mathrm{psyh} \& A \mathrm{~N}=2010-24918-001 \&$ site=ehost-live.

[52] Kaufman NK, Rohde P, Seeley JR, Clarke GN, Stice E. Potential mediators of cognitive-behavioral therapy for adolescents with comorbid major depression and conduct disorder. J Consult Clin Psychol 2005;73(Feb (1))38-46. [Internet], Available from http://search.ebscohost.com/login.aspx? direct=true \&db=psyh\&AN=2005-01321-005\&site=ehost-live.

[53] Stallard P, Skryabina E, Taylor G, Phillips R, Daniels H, Anderson R, et al. Classroom-based cognitive behaviour therapy (FRIENDS): a cluster randomised controlled trial to Prevent Anxiety in Children through Education in Schools (PACES). Lancet Psychiatry 2014;1(Aug (3))185-92. . [Internet], Available from http://search.ebscohost.com/login.aspx? direct=true \&db=psyh\&AN=2015-57591-020\&site=ehost-live.

[54] Szigethy E, Bujoreanu SI, Youk AO, Weisz J, Benhayon D, Fairclough D, et al. Randomized efficacy trial of two psychotherapies for depression in youth with inflammatory bowel disease. J Am Acad Child Adolesc Psychiatry 2014;53(Jul (7))726-35. . [Internet], Available from http://search.ebscohost.com/login. aspx? direct=true $\& \mathrm{db}=\mathrm{psyh} \& \mathrm{AN}=2014-26561-009 \&$ site $=$ ehost-live.

[55] Vostanis P, Feehan C, Grattan E, Bickerton WL. A randomised controlled outpatient trial of cognitive-behavioural treatment for children and adolescents with depression: 9-month follow-up. J Affect Disord 1996;40(Sep (1-2))10516. . [Internet], Available from http://search.ebscohost.com/login.aspx? direct=true $\& \mathrm{db}=$ psyh\&AN=1997-07949-012\&site=ehost-live.

[56] Ip P, Chim D, Chan KL, Li TMH, Ho FKW, Voorhees BW, et al. Effectiveness of a culturally attuned Internet-based depression prevention program for Chinese adolescents: a randomized controlled trial. Depress Anxiety 2016;33(Dec(12)) 1123-31. . [Internet], Available from http://search.ebscohost.com/login.aspx? direct=true $\& \mathrm{db}=\mathrm{psyh} \& \mathrm{AN}=2016-44415-001 \&$ site=ehost-live

[57] Wright B, Tindall L, Littlewood E, Allgar V, Abeles P, Trepel D, et al Computerised cognitive-behavioural therapy for depression in adolescents: feasibility results and 4-month outcomes of a UK randomised controlled trial. BMJ Open 2017:7(1)e012834.

[58] Poppelaars M, Tak YR, Lichtwarck-Aschoff A, RCME Engels, Lobel A, Merry SN, et al. A randomized controlled trial comparing two cognitive-behavioral programs for adolescent girls with subclinical depression: a school-based program (Op Volle Kracht) and a computerized program (SPARX). Behav Res Ther 2016;80(May)33-42. . [Internet], Available from http://search.ebscohost. com/login.aspx?direct=true \&db=psyh\&AN=2016-18480-007\&site=ehost-live.

[59] Marchand E, Ng J, Rohde P, Stice E. Effects of an indicated cognitive-behaviora depression prevention program are similar for Asian American, Latino, and European American adolescents. Behav Res Ther 2010;48(Aug (8))821-5. . [Internet], Available from http://search.ebscohost.com/login.aspx? direct=true \&db=psyh\&AN=2010-16826-015\&site=ehost-live.

[60] Rohde P, Stice E, Shaw H, Gau JM. Cognitive-behavioral group depression prevention compared to bibliotherapy and brochure control: nonsignificant effects in pilot effectiveness trial with college students. Behav Res Ther 2014;55(Apr)48-53. . [Internet], Available from http://search.ebscohost.com/ login.aspx?direct=true\&db=psyh\&AN=2014-10093-007\&site=ehost-live.

[61] Curry J, Rohde P, Simons A, Silva S, Vitiello B, Kratochvil C, et al. Predictors and moderators of acute outcome in the treatment for adolescents with depression study (TADS). J Am Acad Child Adolesc Psychiatry 2006;45(Dec (12))1427-39. [Internet], Available from http://search.ebscohost.com/login.aspx? direct=true $\& \mathrm{db}=\mathrm{psyh} \& \mathrm{AN}=2006-22388-005 \&$ site $=$ ehost-live

[62] Singh N, Reece J. Psychotherapy, pharmacotherapy, and their combination for adolescents with major depressive disorder: a meta-analysis. Aust Educ Dev Psychol 2014;31(Jul (1))47-65. . [Internet], Available from http://search. ebscohost.com/login.aspx?direct=true \&db=psyh\&AN=2014-29011 005\&site=ehost-live.

[63] Tindall L, Mikocka-Walus A, McMillan D, Wright B, Hewitt C, Gascoyne S. Is behavioural activation effective in the treatment of depression in young people? A systematic review and meta-analysis. Psychol Psychother Theory, Res Pract 2017;90(4):770-96.

[64] Spielmans GI, McFall JP. A comparative meta-analysis of Clinical Global Impressions change in antidepressant trials. J Nerv Ment Dis 2006;194(Nov) 845-52 0022-3018 (Print).

[65] Ebert DD, Zarski AC, Christensen H, Stikkelbroek Y, Cuijpers P, Berking M, et al. Internet and computer-based cognitive behavioral therapy for anxiety and depression in youth: a meta-analysis of randomized controlled outcome trials. PLoS One 2015;10(Mar (3)). . [Internet], Available from http://search. ebscohost.com/login. aspx?direct=true\&db=psyh\&AN=2015-14065001\&site=ehost-live. 
[66] Manassis K, Lee TC, Bennett K, Zhao XY, Mendlowitz S, Duda S, et al. Types of parental involvement in CBT with anxious youth: a preliminary meta-analysis. J Consult Clin Psychol 2014;82(Dec (6))1163-72. . [Internet], Available from http://search.ebscohost.com/login.aspx?direct=true \&db=psyh\&AN=201420538-001\&site=ehost-live.

[67] Goodyer IM, Reynolds S, Barrett B, Byford S, Dubicka B, Hill J, et al. Cognitive behavioural therapy and short-term psychoanalytical psychotherapy versus brief psychosocial intervention in adolescents with unipolar major depressive disorder (IMPACT): a multicentre, pragmatic, observer-blind, randomised controlled superiori. Lancet Psychiatry 2017;4(Feb (2))109-19. . [Internet], Available from http://search.ebscohost.com/login.aspx? direct=true $\& \mathrm{db}=$ psyh $\& A N=2017-04930-024 \&$ site $=$ ehost-live

[68] Brumariu LE, Kerns KA. Parent-child attachment and internalizing symptoms in childhood and adolescence: a review of empirical findings and future directions. Dev Psychopathol 2010;22(1):177-203.

[69] Brenning K, Soenens B, Braet C, Bosmans G. The role of depressogenic personality and attachment in the intergenerational similarity of depressive symptoms: a study with early adolescents and their mothers Ghent, Belgium. 2011.
[70] Compton SN, March JS, Brent D, Albano AM, Weersing R, Curry J Cognitivebehavioral psychotherapy for anxiety and depressive disorders in children and adolescents: an evidence-based medicine review. J Am Acad Child Adolesc Psychiatry 2004;43(Aug)930-59 0890-8567 (Print).

[71] Hardway CL, Pincus DB, Gallo KP, Comer JS. Parental involvement in intensive treatment for adolescent panic disorder and its impact on depression.J Child Fam Stud 2015;24(Nov (11))3306-17. . [Internet], Available from http://search.ebscohost. $\mathrm{com} /$ login.aspx?direct=true \&db=psyh\&AN=2015-04489-001\&site=ehost-live.

[72] Bockting CL, Hollon SD, Jarrett RB, Kuyken W, Dobson K. A lifetime approach to major depressive disorder: the contributions of psychological interventions in preventing relapse and recurrence. Clin Psychol Rev 2015;41:16-26, doi: http://dx.doi.org/10.1016/j.cpr.2015.02.003 [Internet], Available from.

[73] Bockting CLH, Smid NH, Koeter MWJ, Spinhoven P, Beck AT, Schene AH. Enduring effects of Preventive Cognitive Therapy in adults remitted from recurrent depression: a 10 year follow-up of a randomized controlled trial. J Affect Disord 2015;185:188-94, doi:http://dx.doi.org/10.1016/j. jad.2015.06.048 [Internet], Available from.

[74] Riley RD, Lambert PC, Abo-Zaid G. Meta-analysis of individual participant data: rationale, conduct, and reporting. BMJ 2010;340(7745):521-5. 